\title{
Linkages Between Climate Change, Migration, Environment and Sustainable Development
}

\section{Pham Xuan Phu*}

Department of Rural Development and Natural Resources Management, Faculty of Agriculture and Natural Resources, An Giang University, A Member of Ho Chi Minh

City National University, Vietnam

*Corresponding Author: Pham Xuan Phu, Department of Rural Development and Natural Resources Management, Faculty of Agriculture and Natural Resources, An Giang University, A Member of Ho Chi Minh City National University, Vietnam.
Received: May 24, 2021

Published: May 26, 2021

(C) All rights are reserved by Pham Xuan Phu.
Climate change has become a major concern for the people community in the world. Climate change does have consequence in terms of human migration and mobility and its impact can be expected to increase in the future. However, environmental change will affect migration present and in the future specifically through its influence economic, social, environmental and political drives in condition of context climate change which themselves affect the linkages between climate change, migration, environment and sustainable development in the context of conditional climate change in the future.

Migration is the process of moving within or across borders, either temporality, seasonally or permanently. Migration occurs as a response to economic development as well as to social, cultural and environment causes. Migration, climate change, environment and sustainable development have been major concerns of both researches and policy makers in recent years in the world. The migration trends have four main types of migration such as: (i) Urban- Urban; (ii) Rural - Urban, (iii) Urban - Rural; (iv) Rural - Rural. There are many factors that influence migration. However, there are four main categories as following: principal factors; economic factors; policy factors, environmental factors. Many factors that influence migration are difficult to predict in the context of conditional climate change in the future.

There is a lack of clarity as to the direct influence of climate change, migration, environment and sustainable development for trends and level of migration. There are many debates affect the linkages between climate change, migration, environment and sus- tainable development those who stress the direct impact of social, economic and political in content of climate change. In most have not detail discussion about the linkages between climate change, migration, environment and sustainable development in the context of conditional climate change in order to support decision making the best practice policy for chance of being effective, policies to address climate change, migration influences by environmental change need to address these limitations.

In short, it is important that the linkages between climate change, migration, environment and sustainable development in context and condition climate change become an interesting concern of researchers and policy makers in the field of migration and sustainable in the context of conditional climate change in the future. There are need to involve interdisciplinary research in order to have comprehensive in many aspects to support decision making the best practice policy for the linkages between climate change, migration, environment and sustainable development in the context of conditional climate change.

\section{Volume 5 Issue 6 June 2021} (C) All rights are reserved by Pham Xuan Phu. 